\title{
Non-trocar related major retroperitoneal bleeding during laparoscopic appendectomy
}

\author{
Haytham MA Kaafarani ${ }^{1,2^{*}}$, Julian D'Achille ${ }^{1,2}$, Roger A Graham ${ }^{1,2}$
}

\begin{abstract}
Most of the reported vascular injuries in laparoscopic appendectomies occur during trocar or Veress needle insertions. As laparoscopy continues to evolve, it is essential that surgeons report unusual complications in an effort to raise awareness and guide management of any iatrogenic injury incurred during minimally-invasive procedures. We report the case of a patient who sustained a major non-trocar related retroperitoneal vascular injury during a routine $L A$.
\end{abstract}

\section{Introduction}

Laparoscopic appendectomy (LA) has gained widespread acceptance in the last 2 decades. Multiple trials and meta-analyses have suggested that the laparoscopic approach offers patients a lower risk of surgical site infection, less postoperative pain, a shorter length of stay and earlier return to work when compared to open appendectomy (OA) [1-6]. Nonetheless, the same studies found higher rates of intra-abdominal abscesses and vascular injuries with LA. Most of the reported vascular injuries in laparoscopy occur during trocar or Veress needle insertions [7]. For patients over the age of 65, population-based studies have even suggested a lower mortality with LA [8]. As laparoscopy continues to evolve, it is essential that surgeons report unusual complications in an effort to raise awareness and guide management of any iatrogenic injury incurred during minimally-invasive procedures. We report the case of a patient who sustained a major non-trocar related retroperitoneal vascular injury during a routine LA.

\section{Case Report}

The patient is a 38 year old obese male, otherwise healthy, who presented with a 24 hour history of right lower quadrant pain and anorexia. His laboratory workup revealed a leukocytosis with eighty percent neutrophilia. On abdominal examination, the patient had localized tenderness lateral to McBurney's point with a positive psoas sign. A computed tomography scan

\footnotetext{
* Correspondence: hkaafarani@tuftsmedicalcenter.org

${ }^{1}$ Department of Surgery, Tufts Medical Center, Boston, MA, USA

Full list of author information is available at the end of the article
}

confirmed the presence of a $16 \mathrm{~mm}$ enlarged appendix with signs of surrounding inflammation [Figure 1]. The patient was promptly taken to the operating room for a LA. A $12 \mathrm{~mm}$ periumbilical trocar was placed under direct vision followed by placement of a $5 \mathrm{~mm}$ suprapubic port and a $5 \mathrm{~mm}$ left lower quadrant port. The peritoneal cavity was insufflated with carbon dioxide to a pressure of $15 \mathrm{~mm} \mathrm{Hg}$. Upon exploration of the abdomen, the appendix was confirmed to be retrocolic in location, significantly inflamed, and adherent to the posterolateral abdominal wall. As the appendix was bluntly mobilized and freed from its posterolateral attachment, a sudden small amount of venous bleeding was noted to originate behind the cecum. After the appendectomy was completed in the usual manner using two endoGIA $^{\mathrm{TM}}$ stapler loads, we focused our attention on identifying and controlling the bleeding. Upon close inspection, both staple lines appeared intact, and the bleeding was confirmed to be retroperitoneal in location, and more significant in severity than initially suspected. Repetitive attempts to expose and identify the bleeding vessel laparoscopically failed. At this point, we proceeded with a transverse Rocky-Davis muscle-splitting open incision. A Bookwalter retractor was placed, and exposure was ultimately achieved despite the patient's large body habitus (body mass index $=42 \mathrm{~kg} / \mathrm{m}^{2}$ ). The bleeding vessel was identified as the right gonadal vein which had apparently avulsed upon mobilization of the retrocolic appendix. The testicular vein was sutureligated with 3-0 vicryl sutures with cessation of the bleeding. Care was taken to avoid injuring the ureter. By the end of the procedure, the patient had lost $1200 \mathrm{ml}$ 


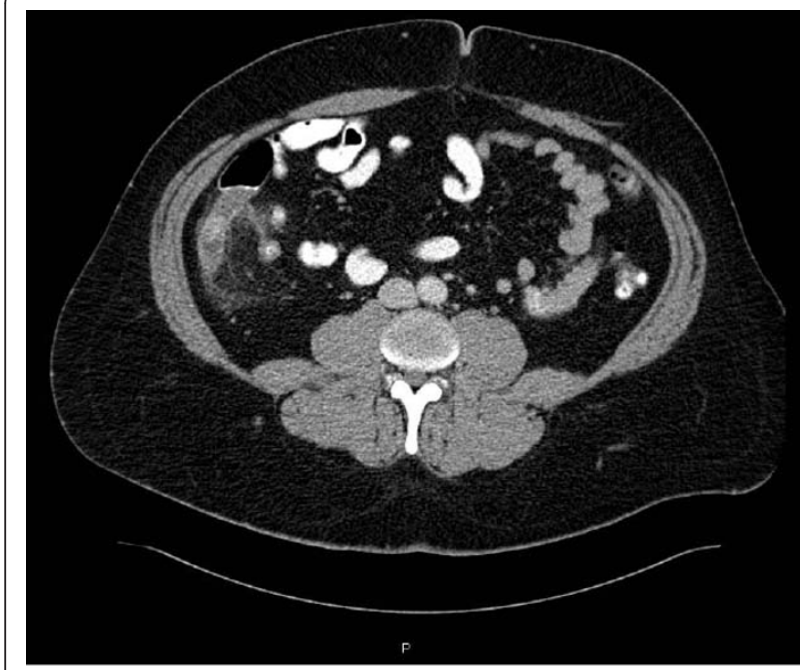

Figure 1 Computed Tomography image showing the enlarged and inflamed appendix.

of blood and had received two units of packed red blood cells. The patient did well after the procedure and was discharged home on the second postoperative day in stable condition without any major sequelae.

\section{Discussion}

After almost two centuries of performing appendectomies, surgeons started resecting the inflamed appendix laparoscopically in the late 1980's. Whether the laparoscopic approach is superior, equivalent or inferior to the open approach in terms of outcomes remains controversial. Several trials have consistently showed that LA, despite being associated with a longer operative time, provides patients with a faster recovery and earlier return to routine activities when compared to OA [1-6]. In a systematic review of randomized trials conducted by Sauerland et al, the rate of superficial surgical site infection was decreased by half, but the rate of deep surgical site infections (intra-abdominal abscesses) was three times higher in LA as compared to OA [5]. On the other hand, a more recent study that used the Nationwide Inpatient Sample database from 2000 to 2005 suggested that the overall rate of complications is $7 \%$ higher with LA [9]. This same study of more than 132,000 appendectomies also found that the cost of LA was $22 \%$ higher than OA in uncomplicated appendicitis and 9\% higher in complicated appendicitis. More importantly, laparoscopy has been associated with a 0.1 to $1 \%$ risk of intra-abdominal or retroperitoneal injuries, including major vessel injury [10-12]. Most of these injuries have been reported to occur during the initial trocar or Veress needle insertion, and many resulted in major morbidity to the patient. Whether LA or OA is the "standard" treatment for acute appendicitis remains controversial, and resolving that matter will probably require rigorous valuation (assigning "values" to the severity of specific complications) and severity weighting of the complication profile of each approach in the setting of a randomized trial [13].

The appendix is reported to be "hidden" in a retroperitoneal, retroileal, retrocecal or retrocolic location in up to $30 \%$ of cases [14]. The terms retrocecal, retroperitoneal and retrocolic have been and continue to be used in literature interchangeably. However, in a 1938 report, William B. Marbury defined retrocecal as being limited by the caput cecum and retrocolic as extending superiorly posterior to the ascending colon [15]. Most retrocolic appendices are also retroperitoneal, while most retrocecal appendices are intraperitoneal.

The patient we report in this paper had a major vascular retroperitoneal injury resulting in significant hemorrhage. The injury likely resulted from avulsion of the retroperitoneal gonadal vessel during dissection of the inflamed retrocolic appendix rather than from a trocar or Veress needle insertion. Marbury, in his landmark 1938 paper, reported on one patient with a retrocolic appendix who suffered "troublesome" bleeding subsequent to injury to a branch of the ileocecal artery [15]. To the best of our knowledge and following review of the literature, major bleeding during routine blunt dissection of the appendix is very rare but poses potentially significant harm to patients. We recommend that surgeons continue with meticulous dissection of any suspected retroperitoneal or retrocolic appendix. The use of advanced bipolar devices (e.g. Ligasure ${ }^{\mathrm{TM}}$ ) or ultrasonic desiccation instruments (e.g. harmonic scalpel TM) might be of assistance if the appendix is severely inflamed. In addition, conversion to OA should be seriously considered when the patient shows signs of hemodynamic instability or when laparoscopic hemostatic methods fail to adequately expose and control the hemorrhage.

\section{Author details}

${ }^{1}$ Department of Surgery, Tufts Medical Center, Boston, MA, USA. ${ }^{2}$ Tufts University School of Medicine, Boston, MA, USA.

\section{Authors' contributions}

$H K$, JD and RG participated in the care of the patient, including the operative part.

$H K$, JD and RG envisioned the concept of the manuscript.

HK wrote the first draft of the manuscript

$\mathrm{JD}$ and RG critically reviewed the manuscript.

$H K$, JD and RG all read and approved the final manuscript.

\section{Competing interests}

The authors declare that they have no competing interests.

Received: 5 January 2011 Accepted: 22 March 2011

Published: 22 March 2011 


\section{References}

1. Fingerhut A, Millat B, Borrie F: Laparoscopic versus open appendectomy: time to decide. World J Surg 1999, 23:835-845.

2. Frazee RC, Roberts JW, Symmonds RE, et al: A prospective randomized trial comparing open versus laparoscopic appendectomy. Ann Surg 1994, 219(6):725-8.

3. Hellberg A, Rudberg C, Kullman E, Enochsson L, Fenyo G, Graffner H, Hallerback B, Johansson B, Anderberg B, Wenner J, Ringquist I, Sorensen S: Prospective randomized multicentre study of laparoscopic versus open appendectomy. Br J Surg 1999, 86:48-53.

4. Katkhouda N, Mason RJ, Towfigh S, et al: Laparoscopic versus open appendectomy, a prospective randomized double-blind study. Ann Surg 2005, 242:439-449.

5. Sauerland S, Lefering R, Holthausen U, Neugebauer EAM: Laparoscopic vs conventional appendectomy: meta-analysis of randomized controlled trials. Langenbeck's Arch Surg 1998, 383:289-295.

6. Eypasch E, Sauerland S, Lofering R, Neugebauer EAM: Laparoscopic versus open appendectomy: between evidence and common sense. Dig Surg 2002, 19:518-522.

7. Guloglu R, Dilege S, Aksoy M, et al: Major retroperitoneal vascular injuries during laparoscopic cholecystectomy and appendectomy. J Laparoendosc Adv Surg Tech A 2004, 14(2):73-6.

8. Guller U, Hervey S, Purves H, et al: Laparoscopic versus open appendectomy: outcomes comparison based on a large administrative database. Ann Surg 2004, 239:43-52.

9. Sporn E, Petroski GF, Mancini GJ, et al: Laparoscopic appendectomy-is it worth the cost? Trend analysis in the US from 2000 to 2005. J Am Coll Surg 2009, 208(2):179-85.

10. Sandadi S, Johannigman JA, Wong VL, et al: Recognition and Management of Major Vessel Injury during Laparoscopy. J Minim Invasive Gynecol 2010, 17(6):692-702.

11. Geers J, Holden C: Major vascular injury as a complication of laparoscopic surgery: a report of three cases and review of the literature. Am Surg 1996, 62(5):377-9.

12. Fruhwirth J, Koch G, Mischinger HJ, et al: Vascular complications in minimally invasive surgery. Surg Laparosc Endosc 1997, 7(3):251-4.

13. Kaafarani HM, Hur K, Campasano M, et al: Classification and valuation of postoperative complications in a randomized trial of open versus laparoscopic ventral herniorrhaphy. Hernia 2010, 14(3):231-5.

14. Guidry SP, Poole GV: The anatomy of appendicitis. Am Surg 1994, 60(1):68-71.

15. Marbury WB: The retroperitoneal (retrocolic) appendix. Ann Surg 1938, 107(5):819-28

doi:10.1186/1749-7922-6-9

Cite this article as: Kaafarani et al: Non-trocar related major retroperitoneal bleeding during laparoscopic appendectomy. World Journal of Emergency Surgery 2011 6:9.

\section{Submit your next manuscript to BioMed Central and take full advantage of:}

- Convenient online submission

- Thorough peer review

- No space constraints or color figure charges

- Immediate publication on acceptance

- Inclusion in PubMed, CAS, Scopus and Google Scholar

- Research which is freely available for redistribution

Submit your manuscript at www.biomedcentral.com/submit
Ciomed Central 